\title{
Tribal Population of Mayurbhanj
}

\author{
Mrs.Biswajita Mohanty \\ Research ScholarRavenshaw University, Cuttack,Odisha
}

\begin{abstract}
The tribal societies in India are considered as the weakest sections of the population in terms of common socio-economic and demographic factors such as poverty, illiteracy, lack of developmental facilities and adequate primary health facilities. Being the primitive inhabitant a region cannot develop leaving its tribal far behind. India being the second largest tribal dominated area after Africa is one of the most fascinating Nations of World from anthropological point of view. Similarly Orissa is a tribal dominated State with the largest number of tribal communities. Almost 44.21 per cent of the total land area in Orissa have been declared as Scheduled area. The total tribal population of the State is 8.15 million, who constitute 22.13 per cent of populationThe paper aims to provide a brief profile of tribal population of Mayurbhanj district of Orissa. More specifically it describes certain characteristics of the demographic, socio-cultural life and livelihood of the tribal people living in this district. The principal motivation behind this research work is to explore and suggest a solution for the problems of STs of Mayurbhanj. Finally, the paper finds out the causes of all problems to be illiteracy of the tribal people and suggests some corrective and immediate measures to be undertaken for the overall development of these peoples.
\end{abstract}

Key terms: Socio-economic diversity, Child Sex Ratio, M.L.E, Right to Education (R.T.E.)

\section{INTRODUCTION}

The tribal societies in India are considered as the weakest sections of the population in terms of common socio-economic and demographic factors such as poverty, illiteracy, lack of developmental facilities and adequate primary health facilities. Among the 29 states in India, Orissa being socio-economically backward and culturally sound occupies a unique place in the tribal map of the country having largest number of tribal communities (62 tribes including 13 primitive tribes) with a population of 9.59 million constituting $22.86 \%$ of state's population and $9.17 \%$ of the total tribal population of the country. Out of 30 districts in Orissa, nine are considered as tribal districts \&Mayurbhanj is one of them. This district has the second highest proportion of STs (56.6 per cent) and highest concentration of schedule tribe population.

\section{TRIBAL OF THE DISTRICT:}

With around sixty per cent of its population consisting of scheduled tribes, the study area exhibits a unique physical and socio-economic diversity. Situated in the north-east corner of the state of Odisha, the district shares the inter-state boundary with Jharkhand and West Bengal. Influence of the culture of these two bordering states is well marked in the adjoining areas of this district of Mayurbhanj. The extension of the Chottanagpur plateau situated in the north, the presence of great Similipal massif in the center and the location of river basins of the Budhabalang and the Kharkai in the east, exhibit unique topographic variations. There are archaeological evidences in the shape of crude tools hewn out of stone to testify that the region was inhabited over five thousand years back. Even today at some places in this area, people are still roaming in the forests in search of food as were practiced hundreds of years back. Side by side, there are people blowing up hill tops and looking under the surface for minerals which go into gigantic furnaces to produce materials for modern society.The district is endowed with rich forest, which has provided a favourable physical environment and resource base conducive to the tribal communities. The district has a total forest area of $4392.13 \mathrm{sq} \mathrm{kms}$ in 2009 which is $42.16 \%$ of total geographical area of the district. Out of the total forest area, reserved forest covers $3330.14 \mathrm{sq} \mathrm{km}$ and protected forest covers $245.06 \mathrm{sq} \mathrm{km}$ and the rest $816.93 \mathrm{sq} \mathrm{km}$ belongs to miscellaneous group.Mayurbhanj is one of the tribal districts of Odisha, which constitutes 58.58percent of tribal population in the district as against 22.85percent in the state during 2011. According to 2011 census the percentage of scheduled tribe population to the total population in the district constitute 58.58percent as against 22.85 percent in the State. 
table:1 Blockwise ST population percentage of Mayurbhanj in 2011

\begin{tabular}{|c|c|c|}
\hline Sl. No. & Name of the Blocks & $\begin{array}{l}\text { ST Population } \\
\text { Percentage }\end{array}$ \\
\hline 1 & Tiring & 74.56 \\
\hline 2 & Bahalda & 58.05 \\
\hline 3 & Jamada & 73.46 \\
\hline 4 & Rairangpur & 42.25 \\
\hline 5 & Bijotola & 75.75 \\
\hline 6 & Kusumi & 64.17 \\
\hline 7 & Bisoi & 69.35 \\
\hline 8 & Jashipur & 68.37 \\
\hline 9 & Raruan & 53.63 \\
\hline 10 & Sukruli & 62.97 \\
\hline 11 & Karanjia & 60.12 \\
\hline 12 & Thakurmunda & 74.92 \\
\hline 13 & Kaptipada & 66.60 \\
\hline 14 & Udala & 67.12 \\
\hline 15 & Gopabandhunagar & 55.36 \\
\hline 16 & Khunta & 79.02 \\
\hline 17 & Samakhunta & 66.73 \\
\hline 18 & Bangiriposi & 69.65 \\
\hline 19 & Sarasakana & 57.86 \\
\hline 20 & Kuliana & 66.28 \\
\hline 21 & Suliapada & 40.51 \\
\hline 22 & Baripada & 38.74 \\
\hline 23 & Badasahi & 50.68 \\
\hline 24 & Betnoti & 41.13 \\
\hline 25 & Rashagovindpur & 54.61 \\
\hline 26 & Murada & 44.03 \\
\hline \multicolumn{2}{|r|}{ Mayurbhanj } & 55.58 \\
\hline
\end{tabular}

The total population of the district as per 2011 census is 25, 19,738 (Rural - 23,26,842, Urban 1,92,896) out of which 12, 56,213 are Male (Rural - 11,57,576 \& Urban-98,637) and 12, 63,525 are female (Rural -1169266 \& Urban- 94259). But the Scheduled Tribe Population of the district is 14,79,576 (Rural 1439002 \& Urban- 40574) out of which 730487 are Male (Rural- 710396 \& Urban -20091) and 749089 are Female (Rural-728606 \& Urban -20483).

Out of 26 Blocks, the tribal are mostly concentrated in Udala, Khunta,Bijatala,Jamda,Baripada,Bangiriposi,Bisoi,Jashipur,Kuliana,Samakhunta,Kaptipada,Kusumi,Thakurmun da and Karanjia, where their population is more than $60 \%$ per cent of the total population of respective Blocks.

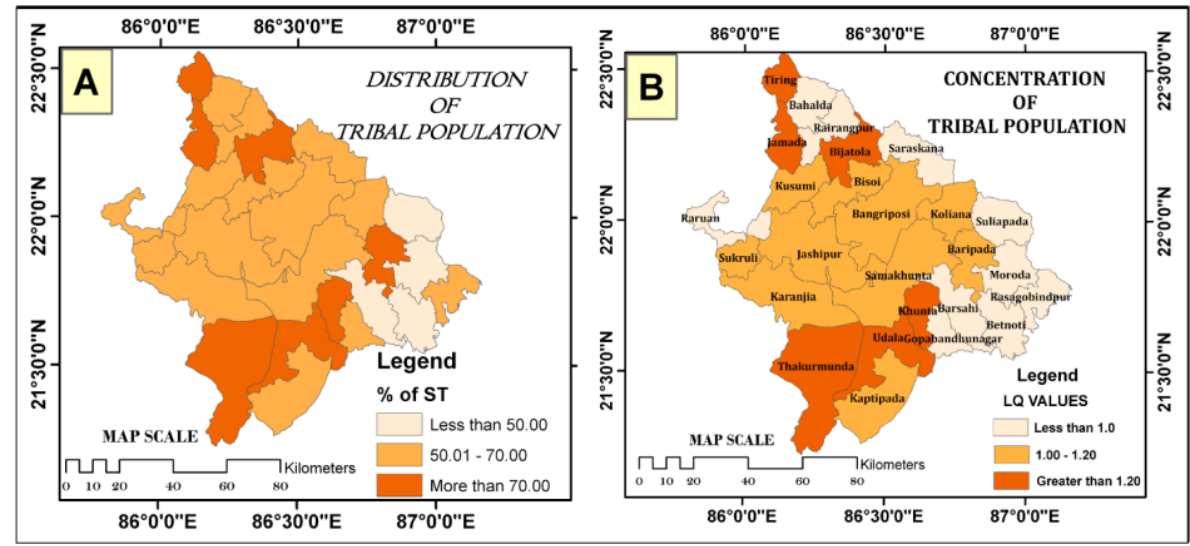

Fig:1 Block-wise Distribution \& Concentration of Tribes in Mayurbhanj 
The majority tribals of Mayurbhanj are the Santals, Kolha, Bathudi and Bhumija.The santals are the main inhabitant of Bijatola block where they constitute about $77 \%$ of its total population. Their dialect belongs to that of the Austro-Asiatic group. Their dialect has been derived from old Kherwali language which had a similarity with other mundari speaking people. Santals do not have any written literature, though their traditional legends (binti) are current among them. Their traditional lore has been handed down orally from generation to generation. Santal is the largest tribes of the district scattered all over Mayurbhanj. Their main occupation is agriculture and agricultural labourer. They are very conscious about their identity and culture. Santal is one of the largest and advanced tribes of India too. They developed their own script Olchiki and have been continuing language movement in Eastern India.The kolhas are generally found in Jashipur block. About 68\% of the block population are kolhas. The Kolha tribes has their own tribal dialect which is used to converse with the people of this community. For them, English has assumed the status of secondary language. Unlike many of the tribes of the region, these Kolha are less proficient in the field of academics and education.

The Bathudi are one of the greatly Hinduised tribes of Orissa depending primarily on settled cultivation and agricultural wage-earning. Their main concentration is is Panchpir ( Karanjia) where they constitute about $62 \%$ of the population. They have no mother tongue of their own but speak Oriya and they have no knowledge if their fore fathers had any other language as their mother tongue. The main occupation of the bathudis is settled agriculture. Among of land owned by most of the families is not sufficient to meet all requirements.

The Bhumija just like any other tribes of the mountainous region of India, these Bhumija tribes too have adapted the profession of shifting cultivation. Seeing the degradation of the landscapes due to rampant cultivation, in the present day, many of these Bhumija tribes sustain their living by gathering and also selling various non timber forest products in the local markets. The people of this tribal group converse in Halbi language which is an amalgamation of Marathi language, Chhattisgarhi language and Oriya language.

\section{SEX RATIO AMONG TRIBAL}

The sex ratio in this tribal dominated district is a surprising fact where the female outnumbers the male. The figure seems to be erratic when we look into the child sex ratio of these blocks. The reason behind such a change may be due to the out migration of the males in search of livelihood or due to the exposure of the males to risk-full occupations in forests and mines. Since pre natal sex determination is not so popularly used among tribal the lack of after care provided to girl children during infant and childhood stage may be the cause of high mortality among them leading to the low sex ratio.

Table:2 Child sex ratio and sex ratio (ST), 2011

\begin{tabular}{|l|c|c|}
\hline \multicolumn{1}{|c|}{ Category } & Child Sex Ratio & Sex ratio \\
\hline Bathudi & 975 & 1019 \\
\hline Kolha & 958 & 1024 \\
\hline Santal & 958 & 1026 \\
\hline Bhumija & 951 & 1002 \\
\hline
\end{tabular}

IV.

LITERACY AMONG TRIBAL

One of the major constraints of tribal education at the planning level is the adoption of a dual system of administration. Due to the language barrier the tribal children are unable to establish communication link with the teacher and thus leading to the termination of their education in some point or the other.

The disparity in literacy level among the tribal of Mayurbhanj is evident from the following table:

Table:3 Literacy among Tribal in Mayurbhanj (1961-2011)

\begin{tabular}{|c|c|c|}
\hline \multirow{2}{*}{ Year } & \multicolumn{2}{|c|}{ Literacy } \\
\cline { 2 - 3 } & Total & Tribal \\
\hline 1961 & 14.18 & 7.10 \\
\hline 1971 & 18.05 & 9.63 \\
\hline 1981 & 25.71 & 14.50 \\
\hline 1991 & 37.88 & 24.10 \\
\hline 2001 & 51.91 & 38.80 \\
\hline 2011 & 63.17 & 53.10 \\
\hline
\end{tabular}

Though the tribals constitute a major part of the population still a low literacy among them indicates how they are far behind the mainstream in terms of education. If dropout rate is considered then the average dropout rate in Mayurbhanj at elementary level is 2.64(2.66 for boys and 2.63 for girls), but in case of S.T. the dropout rate stands at 4.77(4.61 for boys and 9.16 for girls). The major reason behind the poor tribal literacy in Mayurbhanj is 
manifold. They may be School Curriculum, Medium of instruction, the location of schools from the Villages, Infrastructure Problems, economic Condition of parents etc.Medium of instruction is one of the important constraints of tribal children which prevents them access to education. School curriculum is also not convenient for the tribal children. The Location schools create a hindrance for the children of a tribal village to attend the school in a neighbouring village. Certain infrastructural inadequacies like lack of accommodation for library and reading room, workshops, teachers' common room, rooms for indoor games, developed playground, septic latrines, modern educational aids, and audio-visual gadgets and poor state of maintenance of existing infrastructure not only causes inconvenience to the students and teachers, it is also reflected in lack of interest and attachment of the tribal students in the educational situation. Lack of health awareness and healthy habits causes regular health problem for the tribal children. Some of the tribal parents need the help of their children in household work and help at the time of harvest but the holiday pattern and school timings is not suitable to them. The economic condition of tribal people is so poor that they do not desire to spare their children or their labour power and allow them to attend schools. As education does not yield any immediate economic return, the tribal parents prefer to engage their children in remunerative employment which supplements the family income. In the remote tribal areas the teacher absenteeism is a regular phenomenon and this affects largely the quality of education.

\section{SPECIAL PROGRAMME FOR TRIBAL LITERACY IN MAYURBHANJ:}

With the enactment of Right to Education Act, it has now become the mandate to provide free \& compulsory education to every child in the age group of 6-14 year. Though it is the right of every child to get free and compulsory education still there are so many challenges in Mayurbhanj to bring all them into the fold of elementary education. Keeping in view to comply the RTE, district administration has launched the Massive Enrolment \& Retention Drive programme "Mu Bi Padhibi" in convergence with ST/SC Dev., W \& CD, Labour \& Panchayat Raj Deptt. on 1st April 2013.

Other major steps initiated are provision of introduction of MLE where difference in school language and home language. Class-I to III text books are developed in Ol-Chiki script for the tribe Santali. 100 schools adopted Ol-Chiki as one of the Medium of instruction.

The basic objective of these programme are:

- To identify \& enrol the never enrolled and drop-out children (6 - 14 yrs. )

- To rescue \& mainstream the children working in hotel/dhaba/garage and other hazardous places.

- To retain each and every child in school and reduce drop-outs at every stage.

- To ensure the teachers \& students attendance through effective monitoring.

Some suggestions for improvement of tribal education are :

- Proper campaign should be organized to create awareness about the importance of education.

The attitude of the tribal parents toward education should be improved through proper counselling and guidance.All study materials should be supplied in local languages of tribes.

Modification of School Curriculum, Medium of instruction and holiday pattern in tribal dominated area is highly needed. It is suggested to appoint more tribal teachers and female teachers in the tribal areas. Since higher education among the tribes is less, special ST scholarships should be provided to the tribal students perusing higher education, particularly in medical, engineering, and other vocational streams.More residential schools should be established in each states and districts and extended up to PG level in tribal areas. - Social security of students, especially of adolescent girls is of great concern in residential schools. - Higher level officials should check the functioning of schools frequently relating to the teaching methods, working hours, and attendance registers.

\section{REFERENCE:}

[1] Jha, J., Jhingran, D. (2002), Elementary Education for the Poorest and Other Deprived Groups, Centre for Policy Research. New Delhi.

[2] Lal, M. (2005), Education-The Inclusive Growth Strategy for the economically and socially disadvantaged in the Society

[3] Behera A.K.(2015 )Primary Education among Tribal People of Mayurbhanj District of Odisha: An Evaluative Study, International Journal of Humanities and Social Science Invention 